\title{
MATERNAL MORTALITY: LEVELS, CAUSES AND PROMISING INTERVENTIONS
}

\author{
BARBARA E. KWAST \\ Maternal and Child Health Unit, World Health Organization, Geneva
}

\section{Introduction}

About two-thirds of the world's population live in areas where registration of vital statistics is unsatisfactory (Tietze, 1977), and in many countries such statistics from rural areas are unavailable or grossly underestimated (WHO, 1971). Most of the women who die in pregnancy and childbirth are poor and live in remote areas or city slums. Their deaths are accorded little importance and fail to enter registers.

The majority of data originate from health institutions. The maternal mortality reported in these hospitals may be disproportionately high as they are located in cities or towns where services are more accessible and accepted than in rural areas. For example, obstetric emergency referrals from district and provincial hospitals in Kenya to the Kenyatta National Hospital in Nairobi constituted 3\% of the total deliveries but were responsible for $59 \%$ of the total maternal deaths in the hospital (Aggarwal, 1980). Such misleading data arise because hospitals are often considered as the last resort for a moribund woman in a grave emergency.

Civil registration data, where they exist, are almost always incomplete; even in the USA it has been shown that $25 \%$ of maternal deaths are not registered (Rubin et al., 1981). A recent community study in Jamaica revealed a rate of 102 per 100,000 live births, over twice the official rate of 50 (Walker et al., 1986). Varying degrees of plausibility apply to official government or UN estimates for maternal mortality in many countries, where fictitious figures may be reported for various reasons. For example, a household sample survey in Addis Ababa revealed a maternal mortality of 566 per 100,000 live births, while the official figure was 2000 , which seems unrealistic even if maternal mortality is presumed to be higher in rural areas (Kwast et al., 1985).

\section{Definitions}

International comparisons of maternal mortality can be made only on the basis of rather crude and inaccurate figures. For sound analysis, care must be taken that figures have been collected, tabulated, analysed and reported on a comparable basis. The definition of maternal death is "the death of a woman, while pregnant or within 42 days of termination of pregnancy, from any cause related to or aggravated by the pregnancy or its management but not from accidental or incidental causes' (WHO, 1979; DHSS, 1986). The American Medical Association's Committee on Maternal and Child Care (AMA) uses a 90-day limit (WHO, 1981). 
Maternal deaths, as defined above, are generally classified into three main groups. Direct obstetric deaths are maternal deaths resulting from obstetric complications of the pregnant state, labour or puerperium, or from intervention, omission of necessary treatment, incorrect treatment, or a combination of these causes. Indirect obstetric deaths are maternal deaths resulting from previously existing disease or disease that developed during pregnancy, labour or the puerperium. The disease is not directly due to obstetric causes but is aggravated by the physiologic effects of pregnancy. Fortuitous or non-obstetric deaths are excluded from maternal mortality as internationally defined (DHSS, 1986).

The maternal mortality rate (MMR) is usually reported as the ratio of the number of maternal deaths per 100,000 (or 10,000 or 1,000,000) live births (WHO, 1981). The denominator used in England and Wales is that of total live births and stillbirths during the same year. The numerator and denominator do not completely match because: (1) some deaths result from births that occurred during the previous year; (2) deaths from abortion are not associated with any births; and (3) a proportion of maternities give rise to multiple births (Logan \& Lambert, 1979).

The tenth report on Confidential Enquiries into Maternal Deaths in England and Wales shows that maternal deaths are usually related to the number of maternities. This is a count of the number of mothers delivered as distinct from the number of babies born, which of course, includes twins and other multiple births (DHSS, 1986). The denominator as used in England and Wales is possible in countries with accurate registration systems, but as there is a definite reluctance to report stillbirths in many parts of the world (Shamebo, 1978), live births would be the denominator of choice.

In developing countries where obstetric coverage is low and the denominator for the MMR is taken as the number of reported live births, statements of high maternal mortality rates have been made (Thurieux \& Lamotte, 1984). In Niger the hypothesis was advanced that the number of maternal deaths was complete or nearly complete through registration of deaths at all levels of the health network. The birth rate of the country was known through a census. It was suggested that maternal deaths should be related to a denominator which included all births in the country and not only those births registered by the health system. By applying a numerator to a denominator which included all births, the MMR would be appreciably lower and more realistic. Since the MMR is one of the indicators used for the progress towards Health for All by the Year 2000, in five of the six regions of the world as defined by WHO, it is important that the initial status of this indicator be clearly assessed in order to avoid unduly optimistic assessment of this progress.

\section{Maternal mortality levels and trends}

\section{Incidence of maternal mortality in the world}

Information about maternal mortality levels worldwide prior to 1900 is scanty. Historical studies of mortality among members of the ruling houses of Europe show that about 2000 women died per 100,000 live births during the 16th, 17th and 18th centuries and 1470 per 100,000 during the first half of the 19th century (Peller, 1965). For the period 1891-95 maternal mortality in England and Wales was 549 per 100,000 
total births and 394 for the years 1911-13 (Campbell, 1924). In 1911-13, England and Wales had an excess of more than $50 \%$ over Holland and Italy - countries with a very high proportion of medically certified deaths. Although in recent years MMRs have declined dramatically throughout the world, death rates associated with childbearing remain appallingly high in developing countries. Estimates for the average rates in each region and subregion are given in Table 1 (WHO, 1986a).

In developed countries there are between 5 and 30 maternal deaths per 100,000 live births, while in developing countries this figure ranges from 50 to 1000 and even higher. An estimated 500,000 women die each year from causes related to pregnancy and childbirth. All but 6000 of these deaths take place in developing countries which account for $86 \%$ of the world's births and $99 \%$ of maternal deaths.

While in Europe a woman has a life-time risk of one in several thousand of dying from maternal causes, the average risk of a woman in Africa is 1 in 20. Maternal mortality in developing countries can be 100 to 200 times that in developed countries, the widest disparity in all public health statistics. Is it because they are poor that they are allowed to suffer that destruction? Not long ago it was scarcely different in

Table 1. Estimates of maternal mortality, about 1983 (WHO, 1986a)

\begin{tabular}{lccr}
\hline \multicolumn{1}{c}{ Region } & $\begin{array}{c}\text { Live births* } \\
\text { (millions) }\end{array}$ & $\begin{array}{c}\text { Maternal mortality rate } \\
\text { (per 100,000 live births) }\end{array}$ & $\begin{array}{c}\text { Maternal deaths } \\
\text { (thousands) }\end{array}$ \\
\hline Africa & $23 \cdot 4$ & 640 & 150 \\
Northern & $4 \cdot 8$ & 500 & 24 \\
Western & $7 \cdot 6$ & 700 & 54 \\
Eastern & 7 & 660 & 46 \\
Middle & $2 \cdot 6$ & 690 & 18 \\
Southern & $1 \cdot 4$ & 570 & 8 \\
Asia & $73 \cdot 9$ & 420 & 308 \\
Western & $4 \cdot 1$ & 340 & 14 \\
Southern & $35 \cdot 6$ & 650 & 230 \\
South-eastern & $12 \cdot 4$ & 420 & 52 \\
East & $21 \cdot 8$ & 55 & 12 \\
Latin America & $12 \cdot 6$ & 270 & 34 \\
Middle & $3 \cdot 7$ & 240 & 9 \\
Caribbean & $0 \cdot 9$ & 220 & 22 \\
Tropical south & $7 \cdot 1$ & 310 & 1 \\
Temperate south & $0 \cdot 9$ & 110 & 2 \\
Oceania & $0 \cdot 2$ & & 494 \\
Developing countries & $110 \cdot 1$ & 450 & 6 \\
Developed countrics & $18 \cdot 2$ & 30 & 500 \\
World & $128 \cdot 3$ & 390 & \\
\hline
\end{tabular}

* Estimates for 1980-85 from UN demographic indicators of countries: estimates and projections as assessed in 1980. Department of International Economic and Social Affairs, United Nations, New York, 1982. 
industrialized countries - a situation considered sufficiently serious in Wales to call for a detailed enquiry into the general circumstances of that area in the early $1950 \mathrm{~s}$ (Walker et al., 1957).

\section{Africa}

The majority of studies cover the last two decades, from 1960, except for a review of 240 maternal deaths in Uganda for the years 1952-59 (Rendle-Short, 1961), and an account of causes and trends over a 10- and 24-year period respectively, commencing in the early 1950s in South Africa (Lavery, 1970; van Coevereden de Groot, 1979). In The Gambia, a study was carried out in the villages of Keneba and Manduar over a period from 1951 to 1975 (Lamb et al., 1984).

Africa accounts for $30 \%$ of maternal deaths and $18 \%$ of live births in the world. Maternal mortality rates are highest in Africa, with community rates up to and even greater than 1000 per 100,000 live births (Billewicz \& McGregor, 1981; Family Health International, 1983; Ghana Ministry of Health, 1978). The risk of dying from maternal causes is somewhat lower in urban areas of Africa, but a rate of 340 was reported from Ilorin (Adetoro, 1987), and rates over 500 are shown for Addis Ababa and Accra (Kwast, Rochat \& Kidane-Mariam, 1986; Ampofo, 1969).

Intercountry comparisons are difficult and may be grossly misleading, as authors use different definitions both for numerators and denominators of MMRs. One such example is abortion-related mortality. In general, MMRs in northern and southern Africa are a little lower than in western, central and eastern Africa. Overall in Africa, high mortality rates are compounded by high fertility-an average of 6.4 live births per woman, probably achieved after ten pregnancies. An African woman's lifetime risk of dying from pregnancy-related causes may be greater than 1 in 15 .

Asia

In Asia, fertility rates fall below those of Africa, but MMRs nevertheless are high. Densely populated southern Asia accounts for $59 \%$ of the world's maternal deaths and for $41 \%$ of its births. In all countries of this region, except Sri Lanka, the average woman expects to have more than six live births from eight or nine pregnancies. About one in eighteen women will die from a cause related to pregnancy.

Two districts in rural Bangladesh revealed MMRs of 623 and 566 (Khan et al., 1985; Alauddin, 1986). In rural Andhra Pradesh, India, a 1984-85 study found a rate of 874 in rural areas and 545 in urban areas (Bhatia, 1985). The government of Pakistan estimated the national rate to lie between 600 and 800 in 1978. Maternal mortality was shown to be extremely high in remote areas of Nepal (Shah, 1977).

Maternal mortality in east Asia is comparatively low, with China reporting a rate of 59 in rural and 25 in urban areas of 21 provinces (Zhang \& Ding, 1986). Hong Kong and Singapore have statistics comparable with the lowest in Europe. Rates in southeastern and western Asia, whilst on average not as high as in southern Asia, vary between and within countries as has been observed in other continents. Maternal mortality varies in Indonesia between 100 and 800 per 100,000 live births (Cheng Chi, Agoestina \& Hasbin, 1981; Fortney et al., 1986), varying between rural and urban areas. Rates are also high in Democratic Yemen and in the Syrian Arab Republic where the UNFPA estimate is 280 (UNFPA, 1985), while the registration data show a 
MMR of 7 (WHO, 1980a). The data for Malaysia and the Philippines were 63 in 1980 and 80 in 1984 respectively (Malaysia Department of Statistics, 1980). Figures for the Socialist Republic of Vietnam vary between 110 and 378 (UNESCAP, 1984).

Maternal mortality in Asian countries mirrors the variation in rates found among the richest and poorest countries of the world.

\section{Latin America}

Data on maternal mortality in Latin America are mostly based on civil registration. Seven per cent of the world's maternal deaths and $10 \%$ of its live births occur in that region.

The overall estimated maternal mortality in Latin America is $57 \%$ lower than in Africa and 33\% lower than in Asia. These comparisons do not take into account differences in definition and data collection. In total, some 34,000 maternal deaths occur in Latin America each year, about half of them due to illegal abortions. Some specific examples of maternal deaths due to abortion, in the range of one-quarter to one-half, are to be found in Paraguay (8.5 per 100,000 women aged 15-44), Chile (4.8), Trinidad and Tobago (4.6), Colombia (4.1) (Pan American Health Organization, 1982).

The highest maternal mortality based on the vital registration system is to be found in Ecuador (220) and Paraguay (469). Intracountry differences are shown in Brazil: a rate of 310 from rural north-east Brazil compared to 99 in rural Sao Paulo state. The lowest levels are to be found in the temperate areas.

\section{Time trends of maternal mortality in the world}

Figure 1 traces MMRs from selected countries, for which these could be computed, of each region of the world from 1951 to 1980. Standard definitions of maternal mortality acceptable to WHO were used in the collection of these figures which are therefore comparable. Mortality rates for all countries declined.

In a WHO report of maternal deaths and also abortion mortality in 36 countries for two periods, 1951-53 and 1966, nine developing countries were included. Of those countries for which data were available at that time, the highest rates in 1951-53 were $551 \cdot 1,405 \cdot 7$ and $367 \cdot 9$ per 100,000 live births for Ceylon, Trinidad and Tobago, and Chile respectively. The lowest were $67 \cdot 7,69 \cdot 0$ and $73 \cdot 1$ for the United States of America, Sweden and Israel respectively; the median death rate for this period was 125.1. In general there was a declining trend in maternal mortality; a decade later, in $1961-63$, the median rate was $42 \cdot 8$, a decrease of roughly $66 \%$, or $6 \cdot 6 \%$ per annum. In 1961-63, the highest maternal mortality was 290.0 (Chile), and the lowest, 20.5 (Sweden). Between 1961-63 and the year 1966, maternal mortality likewise decreased, but not so fast as in the preceding 10 years. The median death rate in 1966 was 41.0 with the highest rate at 271.8 (Chile) and the lowest at 11.3 (Sweden). From 1961-63 to 1966 , the decrease was about $1.5 \%$ per year. The decrease in maternal mortality since 1951-53 has occurred in all the above mentioned countries in varying degrees, with Sweden registering the largest relative decrease between 1951-53 and 1966 (WHO, 1969). It is postulated that lower mortality rates tended to decline more steeply than higher rates, and that the lower rates are approaching a minimum by current medical technology. Following the approval of a 10-year plan for the Americas, beginning in 


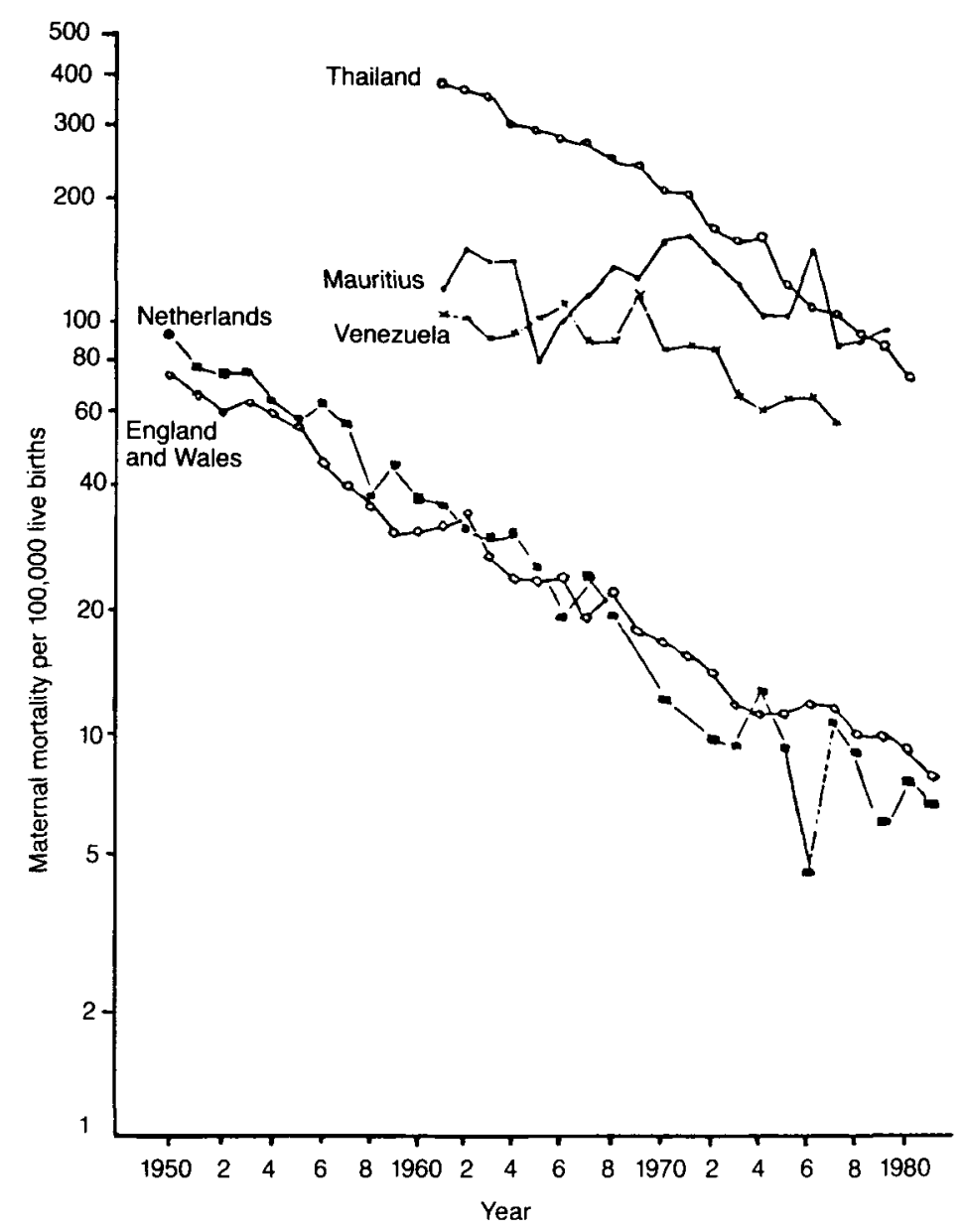

Fig. 1. Maternal mortality from complications of pregnancy, childbirth and puerperium in five selected countries; death rates per 100,000 live births, log scale (Tietze, 1977; WHO, $1973-76,1983)$.

1970, the places where the sharpest declines took place were Costa Rica, Chile, Puerto Rico, Managua and Honduras.

In Asia, MMRs declined considerably in Hong Kong and Singapore, both of which now have rates comparable with developed countries. Impressive declines occurred in Taiwan and Sri Lanka. In Sri Lanka maternal mortality, excluding abortion mortality, fell from a level of 522 in $1950-55$ to 26010 years later and to 87 in 1980 (Sri Lanka Ministry of Health, 1984). In 1950-55 one-quarter of these deaths were due to sepsis and in 1980 there were no deaths from puerperal sepsis. Part of the explanation can be found in the fact that $85 \%$ of births are attended by trained attendants, and $75 \%$ take place in health institutions. In Taiwan, the Provincial Maternal and Child Health Institute reported an MMR of 750 per 100,000 births in 1906, 490 in 1920, 380 in 1930, 310 in 1940, 88 in 1962 and 62 in 1967 (Zhang \& Ding, 
1986). It is noteworthy that $50 \%$ of the decline occurred before 1930 , or before the advent of hospitalized deliveries, blood transfusions and antibiotics. The decline has been attributed to the training of traditional birth attendants.

It is difficult to assess time trends in Africa because in the majority of countries registration of vital statistics on a nationwide basis is lacking. However, a marked decline can be discerned for Kampala (Uganda) when figures from the period 1952-59 are compared with those for the year 1967 (Grech, Galea \& Trussel, 1969). The maternal mortality was $1370 / 100,000$ births and 391 respectively. Trends in maternal mortality covering all ethnic groups, for the years 1953-77 in eight 2- or 3-year periods, in conformity with the practice adopted in the Confidential Enquiries into Maternal Death in England and Wales, were reported in South Africa; abortion mortality was excluded. Maternal mortality was 301, 199, 66 and 46/100,000 deliveries in 1953,1954-56,1957-59 and 1975-77 respectively. The sudden decrease in maternal mortality to below 100 occurred in 1956, largely due to the greater use of the obstetric 'flying squad'. When the time trends of this study and Kampala are compared, it can be seen that, in spite of the decline in both places, maternal mortality remained 4.5 times as high in Uganda. Another study in Ilorin, Nigeria, traced the maternal mortality from 1972 to 1983 and shows a reduction of MMR of $46 \%$, from $630 / 100,000$ in 1972 to 340 in 1983.

\section{Methods for detecting maternal deaths}

The methods for investigating maternal mortality are listed here briefly. Passive reports of deaths are derived from medical certificates, household registration of deaths, church burial registration, newspapers, and hospital/health worker surveillance. Active reports of death come from maternal mortality review committees, reproductive age mortality studies, investigation of all or of selected deaths, linkage of birth certificates with details of women of reproductive age, and surveillance of pregnant women and pregnancy outcomes. Surveys of households and by health workers also provide information.

\section{Principal factors affecting maternal mortality}

As about $72 \%$ of the population in developing countries live in rural areas, the majority of deceased women originate from rural areas. The general background of socioeconomic disadvantage, sociocultural problems, adverse traditional attitudes and low status of women are important determinants: yet for most rural women inequality of health services and maldistribution of health staff, between rural and urban areas, cause critical problems of access to life-saving procedures in emergency during childbirth.

\section{Pathogenic causes}

Clinical data on causes of death have to be interpreted even more cautiously than those on incidence as differences in collection and coding of data and in diagnostic criteria for the main causes of death are great. Because of cultural and religious constraints, post-mortem examinations are rarely performed. In most maternal deaths, more than one obstetric or medical cause is involved. In comparing rates and 
causes from different periods and studies, changes in the International Classification of Diseases (ICD) code must also be borne in mind. In the Confidential Enquiries into Maternal Deaths in England and Wales, a single main cause of death was allotted by a central committee, taking into account each contributory cause of death identified by the regional and central assessors, and subsequently classified according to the ICD. Since more information was available to the assessors, the main cause of death allocated by them is not necessarily the same as the underlying cause shown in the death certificate. In developing countries where such enquiries or maternal mortality review committees do not exist, the decision on the main cause of death may rely on subjective judgment unless criteria for such decisions have been specified. Even then international comparisons may be flawed. Depending on how the classification is presented, serious misconceptions about causes of death may arise, when, for instance, abortion deaths are included under haemorrhage or sepsis.

A review of the literature emanating from developing countries indicates that haemorrhage, ruptured uterus, puerperal sepsis, eclampsia, and complications of abortion are the five major causes of direct maternal deaths, usually accounting for three-quarters of all maternal deaths. This is substantiated by findings in eleven population-based studies in eight developing countries: Bangladesh, Colombia, Cuba, Egypt, Ethiopia, Indonesia, Jamaica and Papua New Guinea. The average percentage of direct obstetric deaths in rank order was: haemorrhage- $27.8 \%$, of which post-partum haemorrhage accounted for the majority; illegal abortion$18.6 \%$; toxaemia of pregnancy $-16.8 \%$; sepsis and obstructed labour $-11.4 \%$ each; and ruptured uterus $5.8 \%$ (Maine et al., 1987). Hepatic coma, meningitis and diarrhoeal disease were the principal indirect causes. The rank order necessarily varies according to prevailing disease patterns both between and within countries and regions (Kwast \& Stevens, 1987).

In developed countries, decline in deaths from sepsis, haemorrhage and abortion magnifies mortalities from hypertensive diseases of pregnancy, pulmonary embolism, anaesthesia and ectopic pregnancy. A study in the USA showed that anaesthetic complications and thromboembolism accounted for $17 \%$ of all maternal deaths. Pulmonary embolism and anaesthesia accounted for $25.2 \%$ of direct maternal deaths in England and Wales between 1979 and 1981.

\section{Socioeconomic causes}

The effect of socioeconomic status cannot be considered in isolation. Women in the poorest strata of society are likely to have been from birth the least privileged in nutrition, housing, education and social amenities. As a consequence, adverse social factors not only aggravate potentially serious complications of pregnancy, but also act as a deterrent to seeking effective obstetric care. Worse still, if it were sought earlier in pregnancy and advice given about measures to remedy a problem, e.g. anaemia, the women may not be able to comply with the advice, and they may never return to that health worker or health facility. Instead, they may be taken as a last resort in a moribund condition to a different health facility, only to die at the entrance.

In general there appears to be a strong association between the gross national product and mortality levels. The community-based study in Addis Ababa showed that the risk of dying for poor women, maidservants, divorced and widowed women 
was three to six times that for those with an income above the poverty line and for married women. These factors were compounded by the fact that $50 \%$ of pregnancies were unwanted. In Ananthapur, India, it was found that the MMR was 2166/100,000 live births in the most socioeconomically deprived villages, compared to 516 in the most developed ones (Bhatia, 1985).

Throughout the world there appears to be a strong inverse relationship between educational attainment and the level of mortality. This concept holds true generally but not always. In northern Nigeria, maternal mortality amongst women without formal education was four times that in women who were educated. In Addis Ababa, no such difference was detected.

\section{Other risk factors}

Other risk factors associated with maternal mortality and morbidity are women's age, parity and birth interval. The optimal childbearing years are between 20 and 30; outside these ages, the increased risk of dying from causes related to pregnancy and childbirth ranges from two to six times the minimum risk. This increase is more pronounced in countries with high mortality levels, as well as in countries with high birth rates (Nortman, 1974). In India, for every woman giving birth, there are fifteen who are sick or handicapped for life. Morbidity from haemorrhage and eclampsia is considerable, and obstructed labour results in severe long term problems.

High parity is common in developing countries; the total fertility rate in Kenya, Senegal, Thailand, Nicaragua and Fiji, for example, is 6.6, 5.4, 6.0, 5.8 and $6 \cdot 3$ respectively (Buchanan, 1975). The risks of high parity are not unique to grand multiparae but are more common in this group. Nutritional anaemia is more frequently seen in women of high parity; in developing countries anaemia is the underlying cause of $40-50 \%$ of maternal deaths, as opposed to virtually none in developed countries (Bengoa, 1974). In Malaysia, among anaemic obstetric patients only $10 \%$ were primigravidae, but $55 \%$ were women of parity 5 or more (Ong, 1974). Obstructed labour, ruptured uterus and post-partum haemorrhage are serious risks in highly parous women and, coupled with anaemia, will often prove to be fatal.

\section{Maternity care services}

Of the 128 million births in the world each year, 58 million are not attended by a trained person (WHO, 1985). Without assistance of trained personnel, the mothers deliver $66 \%$ of the infants in Africa, $36 \%$ in Latin America and $47 \%$ in south-east Asia; $50 \%$ of maternal deaths occur at home or en route to hospital.

In addition, there is a striking maldistribution of both health manpower and health facilities in developing countries. In several countries in Africa $50-75 \%$ of doctors are in the capital city where not more than $10 \%$ of the population lives (WHO, 1980b). About $80 \%$ of the doctors practise in urban areas in India, where $20 \%$ of the population lives. In 1971, the United States had 28 beds per 1000 births as compared with two to five in the developing countries. Urban bias in the distribution of both facilities and manpower is seen everywhere, for many reasons; housing, education, opportunities for employment, and better earnings are all part of the problem.

One of the most critical factors affecting maternal mortality is the availability of 
antenatal care and its acceptance by the community, and those groups which have the highest mortality least often avail themselves of this care. Maternal and child health services $(\mathrm{MCH})$ may be unavailable or inaccessible in rural areas. Where they are present, waiting times are long, $\mathrm{MCH}$ and family planning services may not be integrated, and women cannot afford the time when they are already overburdened with care of children, agriculture, carrying of water, going to the market and cooking. In Tanzania it was shown that $80 \%$ of high risk women can be selected at their first visit to the antenatal clinic, but this applies only to those who attend. Studies from all continents show that as many as $80 \%$ of women who die have never received antenatal care. There are alarming differences in maternal mortality amongst attenders and non-attenders.

The risk approach will succeed only if there is an efficient referral system which has a social service mechanism to accommodate the disadvantaged. Credibility in a maternity service is lost when the community is aware of risks but has a nonfunctioning health care system, or one requiring payment where there is no money to do so. In Malawi, The Gambia and many other countries, $\mathrm{MCH} / \mathrm{FP}$ services have been free since the end of 1986. A system whereby destitute women can be cared for in an emergency without payment operates in other countries, e.g. Ethiopia. Where there is not even that amenity, poor people in remote areas will continue to die.

Conversely, under-utilization of health services is also a fact in some developing countries. There is no easy explanation for this, but there are some suggestions. Traditional customs are firmly rooted in such societies. Knowledge of beliefs and values of certain rituals is obtained only when confidence and trust has been established between the people and the health workers from outside. Respect for customs related to pregnancy and childbirth has often been neglected in a quest to establish modern concepts and technologies of scientifically skilled maternity care. It is for this reason that the older traditional birth attendant or relative continues to practise in $8490 \%$ of births in some countries. There are deep cultural beliefs of which many outsiders are ignorant. Recognizing that these vary from community to community and that the intensity varies between countries, even highly trained specialists within the country may not know about some of the beliefs. Women in Africa and elsewhere come late for antenatal care as it is customary not to reveal the pregnancy until it is visible.

Where such a high percentage of women are attended by the family in the village, a compromise is essential, considering that at least $10 \%$ of pregnant women will need highly skilled assistance either through caesarean section, vacuum or forceps delivery, blood replacement or anticonvulsant therapy. In deprived populations, the incidence of complications may be as high as $30 \%$.

\section{Status of women and reproductive hehatiour}

Maternal mortality is exacerbated by low contraceptive use in many developing countries. Contraceptive services are not widely available and accessible; neither are they affordable in some situations. Yet, family planning can help to reduce maternal mortality by reducing the number of pregnancies or averting unwanted and high risk pregnancies. Using data from the World Fertility Survey, it was estimated that the overall median proportion of maternal deaths which would be prevented is $29 \%$. 
where currently married women aged 15-49 say that they want no more children but are not using an effective method of contraception (Maine et al., unpublished, 1986). For the eight African, ten Asian, and eight Latin American countries, the median is 17,35 and $33 \%$ respectively (Maine et al., 1987).

Much controversy about the use of family planning exists where a woman's value is based on the number of children she has. A woman wants to have enough children to support her in her old age. Lastly, in polygamous societies (Moslem and others) there is competition among wives to have as many children as possible.

There are still taboos and misconceptions about the various methods of childspacing. Nonetheless a number of countries have started community-based distribution of contraceptives through the primary health care strategy, e.g. Indonesia, Malaysia, Gambia.

Women in general take less advantage of the health services because of insufficient education and information, their dependent financial status, and the custom that in many developing countries the husband makes decisions on the time and place of health care for his wife. This is among the most important reasons why women are brought in as emergencies and in a moribund condition when complications of pregnancy or childbirth have become irreversible.

\section{Promising interventions}

Preventive measures will reduce the number of women developing life-threatening complications, but they will not reduce the incidence to zero. The important principles for a reduction of maternal mortality are to bring life saving obstetric functions as close to the people's homes as possible, and to carry out these functions at the most peripheral level at which they can be undertaken safely and effectively. This level is designated the first referral level.

For example, for obstructed labour, the first referral level fulfils two purposes: (a) implementation of preventive measures and dealing with complications in good time; (b) repairing the damage that was caused by grave neglect. The second purpose should become obsolete as overall improvement of the quality of life of women in the reproductive age group occurs. This first referral level is essential to support the community level and form a link between that and the tertiary level of care.

\section{Essential obstetric functions}

The World Health Organization has become increasingly involved with the problem of maternal mortality during the last decade. Supported by UNFPA, WHO convened the first Interregional Meeting on Prevention of Maternal Mortality, in 1985 (WHO, 1986b). The meeting recommended that WHO should convene a working group to define in greater detail the essential obstetric functions at the first referral levels which are indispensable for the reduction of maternal mortality and morbidity. The working group recommended seven essential functions, mostly life saving in obstetric emergencies (WHO, 1986c).

1. Surgical: caesarean section, surgical treatment of sepsis, repair of high vaginal and cervical tear, laparotomy for repair of ruptured uterus, removal of ectopic pregnancy, and evacuation of uterus in uncomplicated abortion. 
2. Anaesthetic: necessary for most of the surgical and several other essential obstetric functions.

3. Medical treatment: for shock, sepsis, control of hypertensive disorders of pregnancy and eclamptic fits.

4. Blood replacement: administration of blood transfusion and plasma expanders.

5. Manual and assessment functions: manual removal of placenta, vacuum extraction and the use of the composite labourgraph (partograph).

6. Family planning: surgical methods (tubal ligation, vasectomy), IUD, Norplant and other contraceptives.

7. Management of women at high risk: includes provision of maternity waiting homes for timely referral.

The essential obstetric functions relate to the prevention and management of the miajor causes of maternal mortality and morbidity. In addition, neonatal special care is included, as maternal and newborn care are inseparable from requirements for essential obstetric functions.

\section{Implementation}

Essential functions at first referral level of health care require specific skills of health staff, physical facilities, special equipment, essential drugs and supplies. These functions imply that a primary level of maternal care exists and is supported effectively. Requirements will differ among and within countries, depending on the relative importance of maternal mortality, population density, topography and social infrastructure (availability of transport, health staff and health facilities).

Caesarean section is one of the most important keys to the whole question of maternal mortality. In the small rural hospitals in the developing world, it is the major operation that many doctors, medical and clinical assistants or even midwives in isolated places most frequently have to perform. Caesarean section can prevent death from obstructed labour, ruptured uterus, ante-partum haemorrhage and severe hypertensive disease of pregnancy. Yet this life saving procedure has often to be carried out in difficult and primitive conditions, e.g. poor light, poor equipment and lack of blood transfusion and antibiotics to combat shock and infection. Furthermore, emergency procedures are much more complicated and require additional skills among health staff specifically trained to perform caesarean sections. Implementation of programme plans do not necessarily require extension of existing facilities or even new maternity centres. Much of what is required exists and further development depends on organizational capabilities to re-allocate existing resources. A balance between need and services is necessary so that the workload is cost-effective and ensures maintenance of skills to perform the tasks safely. Zaire offers an example of caesarean sections performed safely by nurse-midwives after special training, and the benefits were remarkable in the absence of doctors.

\section{Social infrastructure: referral and transportation}

The maternity waiting home or shelter for pregnant women at risk is vital for those who may need special management or operative delivery and who come from remote areas. This idea is not new and was reported from Nigeria in the early $1960 \mathrm{~s}$. 
The establishment of a maternity village in eastern Nigeria was instrumental in the reduction of maternal mortality in the hospital from 1000 to 100 per 100,000 deliveries (Lawson \& Stewart, 1967). Several examples can be found in Africa. In northern Malawi, for instance, a village community built such a home near a health centre. Upkeep is undertaken by the villagers and the women who stay there; relatives bring food and cook for them. On average, fifteen women await delivery there or are transferred before or during labour to the nearest hospital $100 \mathrm{~km}$ away. Only one maternal death occurred in 3 years, of a woman who was severely anaemic when presenting herself for the first time at the health centre. Women come to the waiting home from as far away as $25 \mathrm{~km}$ during the last month of their pregnancy. They were either self-referred or sent by the traditional birth attendants and all knew that they had a condition which might result in complication either to them or their child. Sometimes a traditional birth attendant operates a clinic with a waiting home, which is regularly visited by a supervising public health nurse-midwife who gives support and continuing education.

People to whom this concept is new may wonder how it can be made a success. Education and information are prerequisites for creating awareness within a community. Through the primary health care strategy, village development committees are formed; they will be the catalysts in such innovative approaches. But as long as there are no general government policies, such admirable initiatives will remain sporadic and of local effect only.

Cuba implemented these strategies on a national scale when, in 1961, all health activities became the responsibility of the Ministry of Health and health services were organized on a regional basis. Maternity mortality fell from 118 to 31 per 100,000 live births between 1962 and 1984 . This $75 \%$ decrease was mainly attributed to the building of maternity waiting homes, improved antenatal care, and better socioeconomic conditions, as well as legal and safe abortion after the liberalization of abortion laws in 1968 (Farnot Cardoso, 1986).

In the West Kiang district of The Gambia maternal mortality remained constant at about 200 per 100,000 births between 1951 and 1975. From 1974 onwards, a physician and a midwife provided 24-hour emergency cover for the 2000 people in the three villages. There was regular controlled surveillance of women, infants and school children. An antenatal clinic was held weekly and pregnant women were examined every 4-6 weeks. At 30 weeks' gestation the women were given a cord pack and its use was explained to both the mother and the traditional midwife. Women requiring hospital admission were transported free. No pregnancy-related death occurred between 1975 and 1983 even though sixteen would have been expected, estimated from the current maternal mortality in rural Gambia. In 1983, nineteen women were transferred to hospital with major complications including severe ante-partum and post-partum haemorrhage, preeclampsia and obstructed labour. This demonstrates the importance of placing skilled staff to work in a rural area and the crucial need for transport where surgical and medical emergency care is unavailable locally (Lamb et al., 1984).

\section{Delegation of essential tasks}

There is usually a shortage of health staff in rural areas for reasons of 
maldistribution, lack of social commitment, or a shortage of doctors. Non-physician health workers could be appropriately trained for the performance of some tasks, competently, safely and efficiently. Manual and assessment skills, for example, can be carried out by well-trained midwives and assistant midwives.

The partograph is used to give early warning of cephalo-pelvic disproportion in several countries in the remotest health centres, or maternities, with good success after intensive teaching and practice. Vacuum extraction can be performed efficiently by midwives. Training in the manual removal of the placenta, as a life saving function in an emergency, should be included in the midwifery training. Through the adaptation of training curricula and changes in regulations and legislation, the midwife's contribution to the reduction of maternal mortality can be fully used and the provision of critically needed services can be promoted.

Organization and supervision of peripheral clinics providing obstetric care are essential tasks of the district medical officer and one of the important keys to the reduction of maternal mortality and morbidity (Larsen, 1987). Supervision covers many responsibilities, including continuing in-service education to encourage staff towards better performance. A maternal death averted by staff in the periphery is rewarded by honour and respect.

\section{Family planning services}

Provision of family planning has been included among the essential obstetric functions, because it is an integral part of MCH services, and because the reduction of maternal mortality from all major causes partly depends on progress in family planning. Family planning services should be widely available and provide a high standard of care. Education and information for the public are prerequisites. Students in training schools should learn about the risks inherent in pregnancy and ways to reduce risk and prevent maternal deaths. If community development workers, agricultural extension workers, school teachers and women's groups were offered training courses they would have an effect at all levels of society in creating awareness and in teaching.

\section{The safe motherhood initiative}

The World Bank, the World Health Organization, and the United Nations Fund for Population Activities jointly sponsored the Safe Motherhood Conference, in Nairobi in 1987, to consider the unacceptably high levels of maternal mortality, and to define objectives and generate action. The challenge is to reduce maternal mortality by approximately $50 \%$ in the next decade (Mahler, 1987).

Decision-makers at local, national and international levels who carry the responsibility for planning, financing, organizing and managing maternity services can determine which causes of maternal mortality need priority action. An accelerated build-up of essential obstetric function is advocated, keeping improvement of maternal health as a central focus. Estimates of the number of women who will die from post-partum haemorrhage, toxaemia and puerperal sepsis, or from abortion, during the 13-year period 1987-2000, if no action is taken, are shown in Table 2. Decentralization of essential obstetric services, promoting maternity waiting homes through community education, and the introduction of 
Table 2. Estimated maternal deaths from major causes, 1987-2000, in developing countries

\begin{tabular}{lcc}
\hline & \multicolumn{2}{c}{ Maternal deaths } \\
\cline { 2 - 3 } \multicolumn{1}{c}{ Cause of death } & $\% *$ & $\begin{array}{c}\text { No. } \\
\text { (million) }\end{array}$ \\
\hline Post-partum hacmorrhage & 27 & $1 \cdot 5$ \\
Abortion & 19 & $1 \cdot 1$ \\
Toxacmia & 17 & $1 \cdot 0$ \\
Puerperal sepsis & 13 & $0 \cdot 7$ \\
Obstructed labour & 17 & $1 \cdot 0$ \\
\hline
\end{tabular}

* Average calculated from eleven population based studies in five developing countries (Maine et al., unpublished).

changes in regulations and legislation to adapt and expand the training and practice of health workers, require a political will and policy commitment. The reduction of maternal mortality by at least $50 \%$ by the turn of the century is an affordable and achievable option.

\section{Acknowledgments}

The author would like to thank all those colleagues in the Family Health Division of WHO who contributed to the paper.

\section{References}

Aid:TORo, O. O. (1987) Maternal mortality a twelve year survey at the University of Ilorin Teaching Hospital (UITH) Nigeria. Int. J. Ginaec. Ohstet. 25. 93.

Aggarwal. V. P. (1980) Obstetric emergency referrals to Kenyatla National Hospital. East. Afr. med. J. 58. 25.

AtacdDIN. M. (1986) Maternal mortality in rural Bangladesh. The Tangail District. Stud. Fam. Plamm. 17. 13.

AMPOFO, D. A. (1969) Causes of maternal deaths and comments. Maternity Hospital, Accra. W. Afr. med. J. 18, 75.

BENGOA, J. M. (1974) The problems of malnutrition. WHO Chronicle, 28, 3.

Bhatia, J. C. (1985) Maternal Mortality in Ananthapur District, Andhra Pradesh, India. Indian Institute of Management. Bangalore. India.

BillewicZ, W. Z. \& MCGregor, 1. A. (1981) The demography of two West African (Gambian) villages. 1951 75. J. hiosoc. Sci. 13. 219.

Buchanan, R. (1975) Effects of Childhearing on Maternal Health. Population Reports Series J, No. 8, pp. 126 139. Department of Medical and Public Affairs, George Washington University Medical Center, Washington, DC.

Campibl. I. J. M. (1924) Matemal Mortalit!. Reports on Public Health and Medical Subjects, No. 25. HM Stationery Office. London. 
Cheng Chi, I., Agoestina, T. \& Hasbin, J. (1981) Maternal mortality at twelve teaching hospitals in Indonesia-an epidemiologic analysis. Int. J. Gynec. Obstet. 19, 259.

Department of Health and Social Security (1986) Report on Confidential Enquiries into Maternal Deaths in England and Wales 1979-1981. Reports on Health and Social Subjects, No. 29. HM Stationery Office, London.

Family Health International (1983) Study in maternal mortality in Senegal. Network, 5, 2.

Farnot Cardoso, U. (1986) Giving birth is safer now. World Health Forum, 7, 348.

Fortney, J. A., Susanti, I., Gadalla, S., Saleh, S. \& Rogrers, S. M. (1986) Reproductive mortality in two developing countries. Am. J. publ. Hlth, 76, 134.

Ghana Ministry of Health (1978) A Primary Health Care Strategy for Ghana. National Health Planning Unit, Accra.

Grech, E. S., Galea, J. \& Trussel, R. R. (1969) Maternal mortality in Uganda. Int. J. G.nec. Obstet. 7, 263.

Khan, A. R., JAHAN, F. A., Begum, S. F. \& JALIL, K. (1985) Maternal mortality in rural Bangladesh. World Health Forum, 6, 325.

Kwast, B. E., Kidane-Mariam, W., Saed Mohammed, E. \& Fowkes, F. G. R. (1985) Epidemiology of maternal mortality in Addis Ababa: a community based study. Ethiop. med. J. 23, 7.

Kwast, B. E., Rochat, R. W. \& Kidane-Mariam, W. (1986) Maternal mortality in Addis Ababa, Ethiopia. Stud. Fam. Plann. 17, 288.

Kwast, B. E. \& Stevens, J. A. (1987) Viral hepatitis as a major cause of maternal mortality in Addis Ababa, Ethiopia. Int. J. Gynec. Obstet. 25, 99.

Lamb, W. H., Lamb, C. M. B., Foord, F. A. \& Whitehead, R. G. (1984) Changes in maternal and child mortality rates in three isolated Gambian villages over ten years. Lancet, i, 912.

LARSEN, J. V. (1987) Supervision of peripheral obstetric units. Tropical Doctor, 17, 77.

LAVERY, D. W. P. (1970) Maternal mortality at Baragwanath Hospital for the period 1951-1968. S. Afr. med. J. 44, 1230.

LAwSON, J. B. \& StewarT, D. B. (1967) In: Obstetrics and Gynaecology in the Tropics, p. 309. Edward Arnold, London.

Logan, W. P. D. \& LAMBert, P. M. (1979) Vital statistics. In: The Theory and Practice of Public Health, 115th edn. Edited by W. Hobson. Oxford University Press, Oxford.

Mahler, H. (1987) The safe motherhood initiative: a call to action. Lancet, i, 668.

Maine, D., Rosenfield, A., Wallace, M., Kimball, A. M., Kwast, B., Papiernik, E. \& White, S. (1987) Prevention of Maternal Deaths in Developing Countries: Program Options and Practical Considerations. Centre for Population and Family Health, University of Columbia, New York.

Malaysia Department of Statistics (1980) Annual Statistical Bulletin, Saranak, 1979, Vol. 16. Kuala Lumpur.

Nortman, D. (1974) Parental Age as a Factor in Pregnancy Outcome and Child Development. Reports on Population/Family Planning, No. 16. Population Council, New York.

ONG, H. C. (1974) Anaemia in pregnancy in an aboriginal population. J. trop. Med. Hyg. 22.

Pan American Health Organization (1982) Health Conditions in the Americas, 1977-1980. Scientific Publication No. 427. PAHO, Washington, DC.

Peller, S. (1965) Births and deaths among Europe's ruling families since 1500. In: Population in History. Aldine, Chicago.

Rendle-Short, C. W. (1961) Causes of maternal deaths among Africans in Kampala. J. Obstet. Gynaec. Br. Commonw: 68, 44.

Rubin, G., McCarthy, B., Shelton, J., Rochat, R. W. \& Terry, J. (1981) The risk of childbearing re-evaluated. Am. J. publ. Hlth, 71, 712 .

Sнaн, M. (1977) Rural Health Needs: Report of a Study in the Primary Health Care Unit of Dhankuta, Nepal. Health Manpower Development Research Project, Tribhuvan University, Kathmandu. 
Shamebo, D. (1978) Fertility and infant mortality rates in Dembia Plain, Gondar. Ethiop. med. J. 16, 95.

Sri Lanka Ministry of Health (1984) Annual Health Bulletin: Sil Lanka 1983. Colombo.

Thurieux, M. C.\& LAmotti, J. M. (1984) Maternal mortality in developing countries: a note on the choice of denominator. Int. J. Epidemiol. 13, 246.

TIETZE, C. (1977) Maternal mortality excluding abortion mortality. World Health Statistical Report, 30, 312 .

United Nations Economic and Soclal Commission for Asia and the Pacific (1984). The Asium and Pacific Atlas of Children in National Development 1984. UNICEF, Bangkok.

United Nations Fund for Population Activities (1985) Syrian Arab Republic: Report of Second Mission on Needs Assessment for Population Assistance. UNFPA, New York.

VAN COl:VERFDEN DE GROOT, H. M. (1979) Trends in maternal mortality in Cape Town. 1955-1957. S. Afi. med. J. 56, 547.

Walkir, A. L., Wriglity, A. J., Marston, A. D., Hirst, K. M. \& Martin, W. J. (1957) Report on Confidential Enquirie's into Maternal Deaths in England and Wales 1952-1954. HM Stationery Office, London.

Walker, G. J. A., Ashley, D. E. C., MCCaw, A. M. \& Bernard, G. W. (1986) Maternal mortality in Jamaica. Lancet, ii, 486.

World Hialth Organization (1969) World Health Statistic's Report, 22, 235.

World Health Organization (1971) World Health Organization Expert Committee on Family Planning in Health Services. WHO Tech. Report Ser. 376, 65.

World Hialth Organization (1973-76) World Health Statistics Annual. WHO, Geneva.

WORLD HEal TH Organization (1979) International Classification of Diseases, Injuries and Causes of Death (ICD9), WHO, Geneva.

World Health Organization (1980a) World Health Statistics Annual-Vital Statistics and Causes of Death. WHO, Geneva.

World Hialth Organization (1980b) Sixth Report on the World Health Situation 1973-1977, Part 1, Global analysis, pp. 127, 183. WHO, Geneva.

World Health Organization (1981) World Health Statistics Quarterly, No. 34, p. 2. Who, Geneva.

Worido Hialth Organization (1983) World Health Statistics Ammal. WHO, Geneva.

World Hi:alth Organization (1985) Corerage of Maternity. Care. Document FHE 85.1. WHO, Geneva.

World Hialth Organization (1986a) Matemal Mortality Rates. Document FHE/86.3. WhO, Geneva.

Worl.d Hial.th Organization (1986b) Precention of Maternal Mortality. Document FHE 86.1. WHO. Geneva.

Worlin Hialth Organization (1986c) Essential Obstetric Functions at First Referral Letel. Document FHE/86.4. WHO, Geneva.

Zhaxg. L. \& DiNg. H. V. (1986) Analysis of cause and rate of regional maternal death in 21 provinces, municipalities and autonomous regions. Chinese J. Obstet. G!naec. 21, 195. 